Supporting Information

\title{
Heating Rate-Controlled Thermal Exfoliation for Foldable Graphene Sponge
}

Wei Wei, ${ }^{\dagger}$ Tuxiang Guan, ${ }^{\dagger}$ Chang Li, ${ }^{\dagger}$ Liming Shen,$^{{ }^{*}}$ and Ningzhong Bao ${ }^{\dagger,,^{*}}$

†State Key Laboratory of Material-Oriented Chemical Engineering, College of Chemical

Engineering, Nanjing Tech University, Nanjing, Jiangsu 210009, P. R. China

‡Institute of Graphene, Jiangsu Industrial Technology Research Institute, Nanjing, Jiangsu 210009,

P. R. China

*Corresponding author:

Tel. \& Fax: +862583172244

E-mail: 1shen@njtech.edu.cn (L. Shen); nzhbao@njtech.edu.cn (N. Bao) 


\section{Contents}

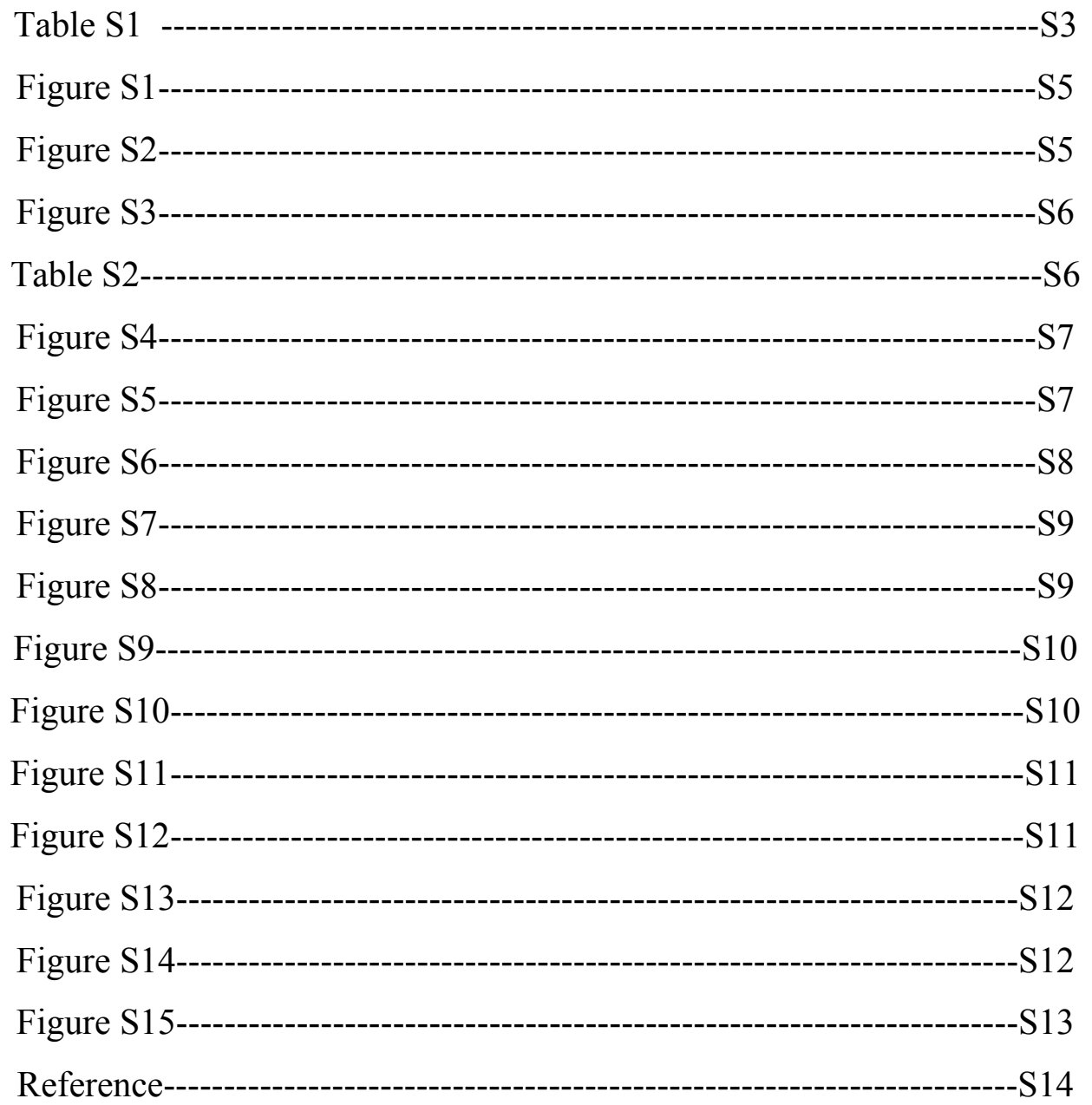


Table S1. Reported morphologies of rGO prepared with the thermal exfoliation of GO.

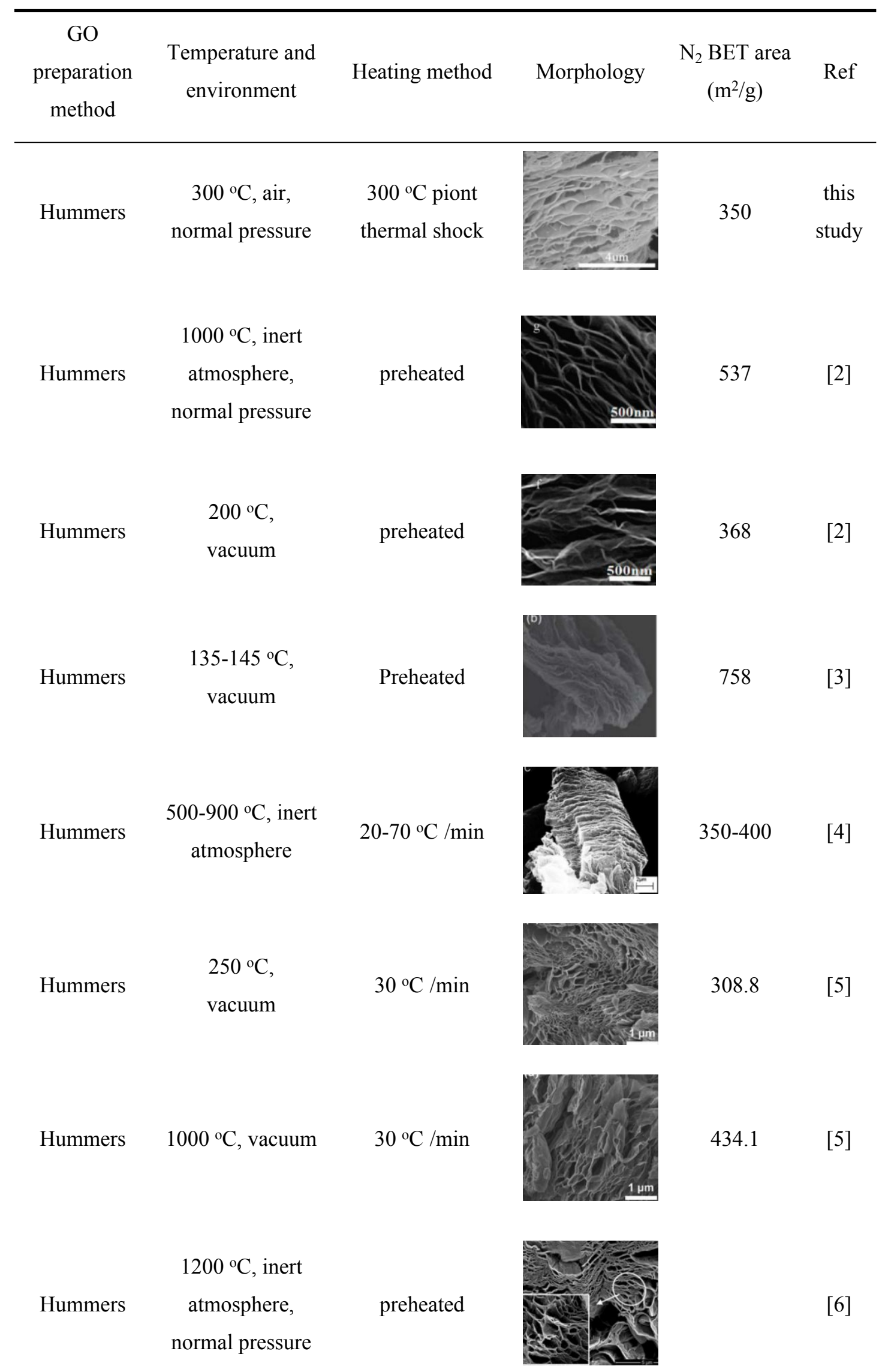




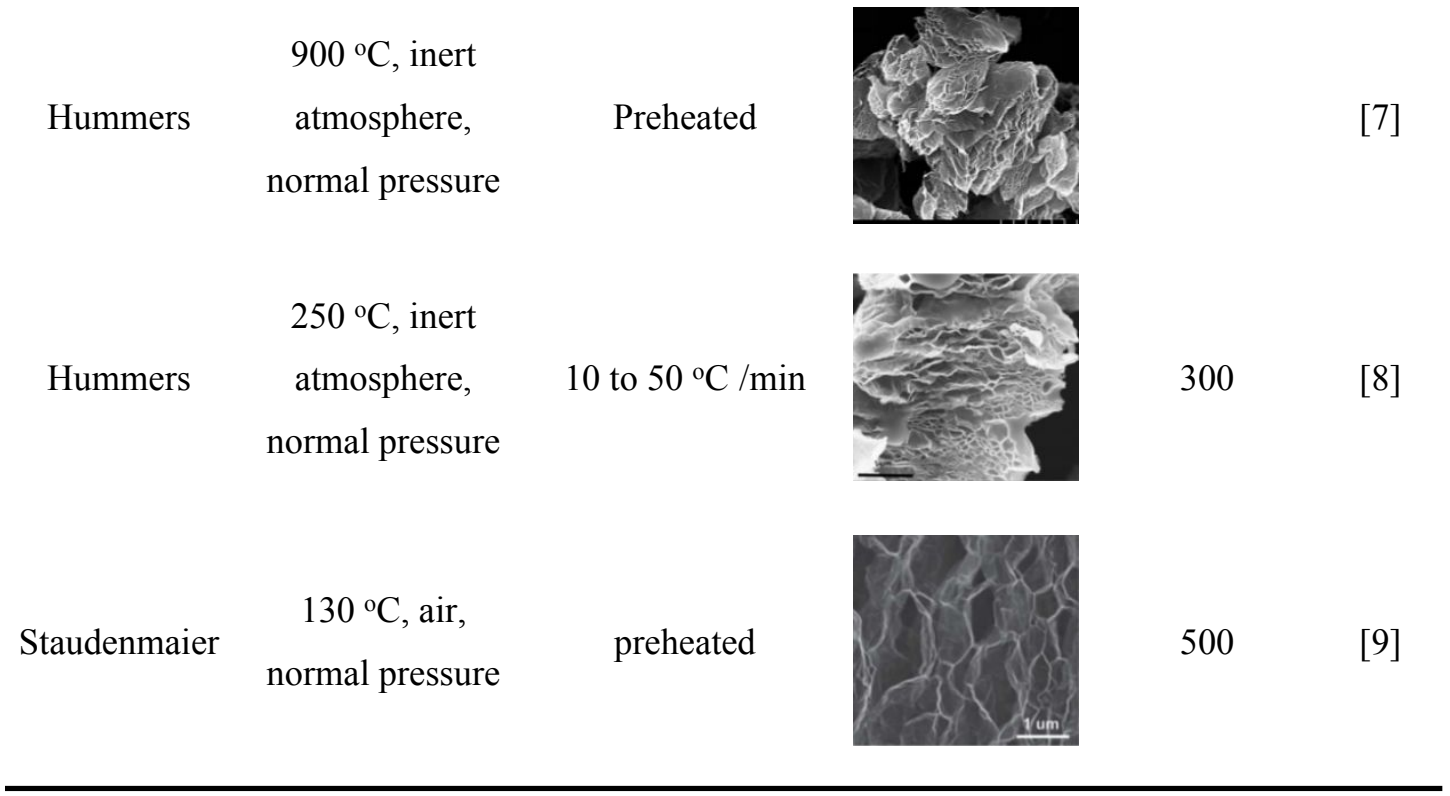




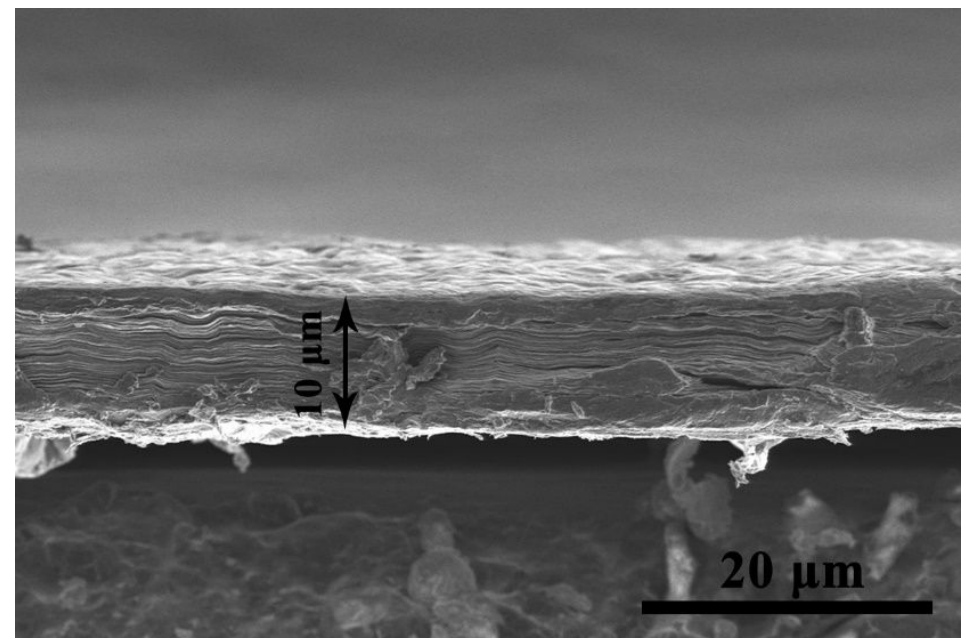

Figure S1. Cross-section SEM image of the dried GO film.
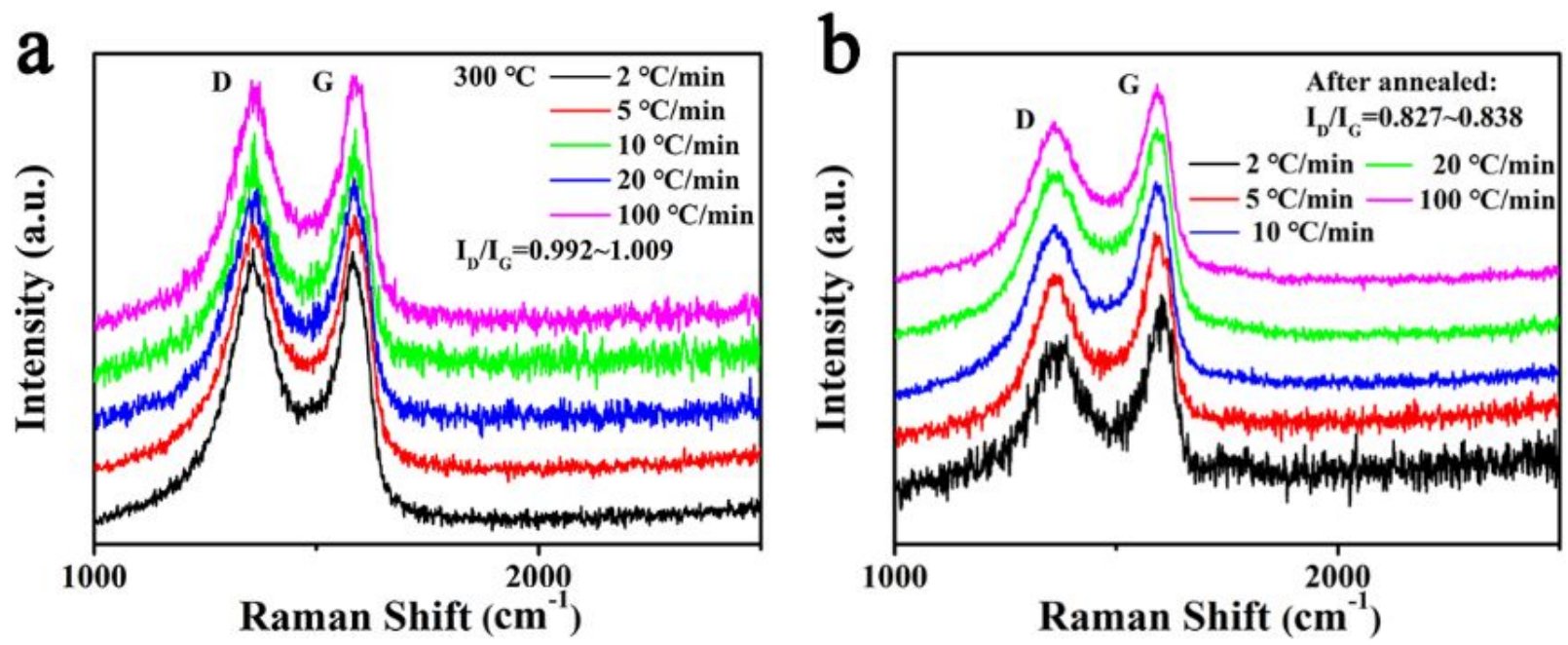

Figure S2. (a) Raman spectrum of GO heated to $300^{\circ} \mathrm{C}$ at different heating rates $(2,5,10,20$, and 100 $\left.{ }^{\circ} \mathrm{C} \cdot \mathrm{min}^{-1}\right)$, (b) Raman spectrum of $\mathrm{GO}$ sponges obtained by annealing at $1050{ }^{\circ} \mathrm{C}$ at different heating rates. 

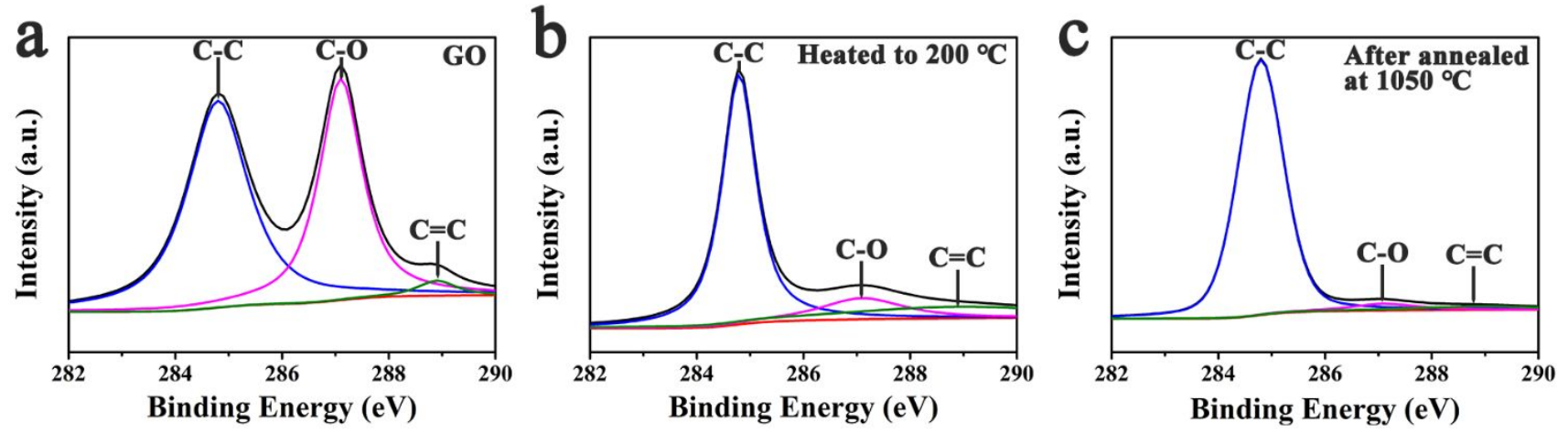

Figure S3. C 1s XPS spectrum of (a) GO, (b) GO heated to $200^{\circ} \mathrm{C}$, (c) GO after annealing at $1050{ }^{\circ} \mathrm{C}$.

Table S2. Data summary from Figure S3.

\begin{tabular}{ccccccc}
\hline \multirow{2}{*}{ Sample } & \multicolumn{2}{c}{$\mathrm{C}-\mathrm{C}$} & \multicolumn{2}{c}{$\mathrm{C}-\mathrm{O}$} & \multicolumn{2}{c}{$\mathrm{C}=\mathrm{O}$} \\
\cline { 2 - 7 } & Peak & Area & Peak & Area & Peak & Area \\
& $(\mathrm{eV})$ & $(\%)$ & $(\mathrm{eV})$ & $(\%)$ & $(\mathrm{eV})$ & $(\%)$ \\
\hline $\mathrm{GO}$ & 284.8 & 55.5 & 287.1 & 42 & 288.9 & 2.5 \\
$200^{\circ} \mathrm{C}$ & 284.8 & 86.5 & 287.1 & 6.9 & 288.9 & 6.6 \\
$1050^{\circ} \mathrm{C}$ & 284.8 & 96.7 & 287.1 & 1.6 & 288.9 & 1.7 \\
\hline
\end{tabular}



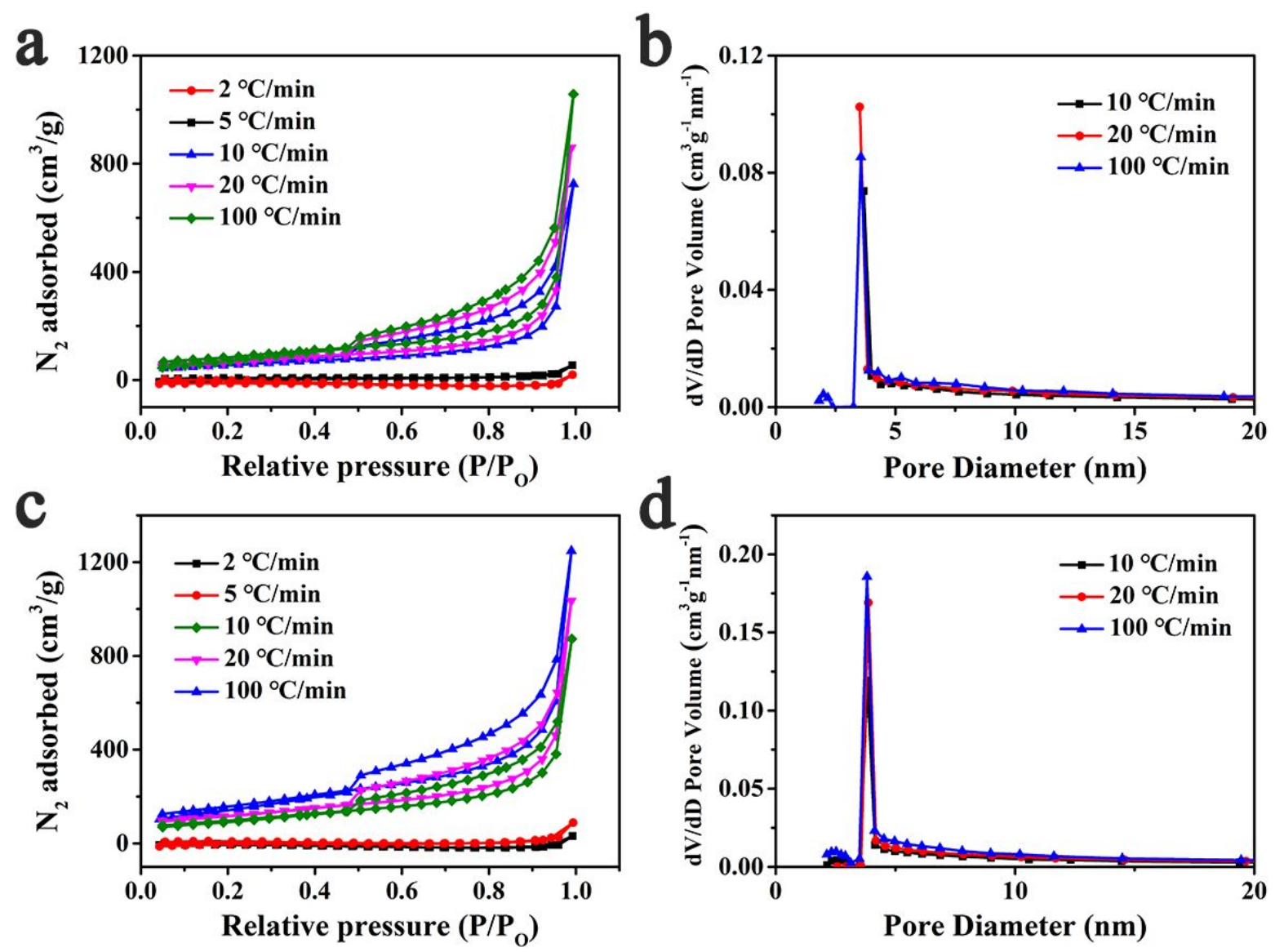

Figure S4. (a) $\mathrm{N}_{2}$ adsorption isotherms of $\mathrm{GO}$ heated to $200{ }^{\circ} \mathrm{C}$ at different heating rates from 2 to 100 ${ }^{\circ} \mathrm{C} \cdot \mathrm{min}^{-1}$, (b) the corresponding products $\mathrm{N}_{2}$ pore size distributions, (c) $\mathrm{N}_{2}$ adsorption isotherms of $\mathrm{GO}$ heated to $1050{ }^{\circ} \mathrm{C}$ at different heating rates from 2 to $100{ }^{\circ} \mathrm{C} \cdot \mathrm{min}^{-1}$, (b) the corresponding products $\mathrm{N}_{2}$ pore size distributions.
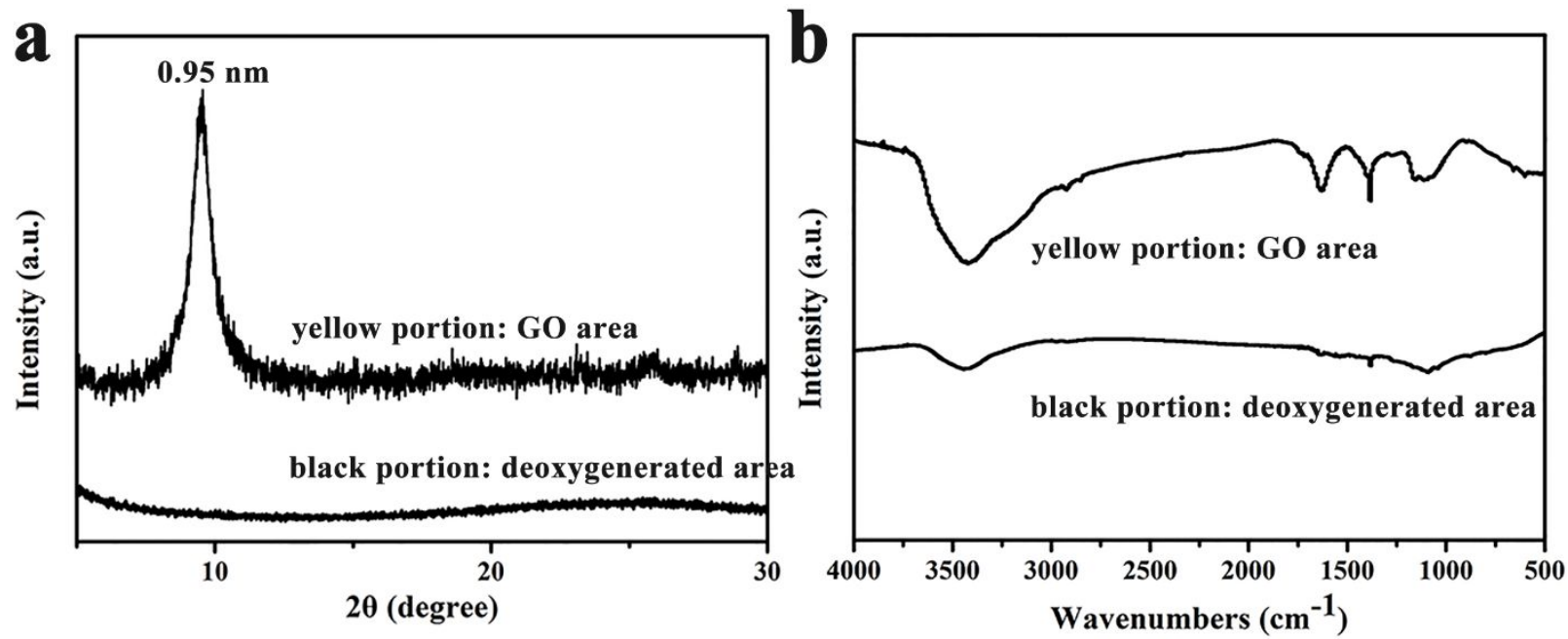

Figure S5. (a) XRD patterns and (b) FT-IR spectra of GO (yellow area of the film in Figure 3b) and rGO (black area of the film in Figure 3b). The internal spacing of GO sheets is $0.95 \mathrm{~nm}$ calculated with the Scherrer Equation. 

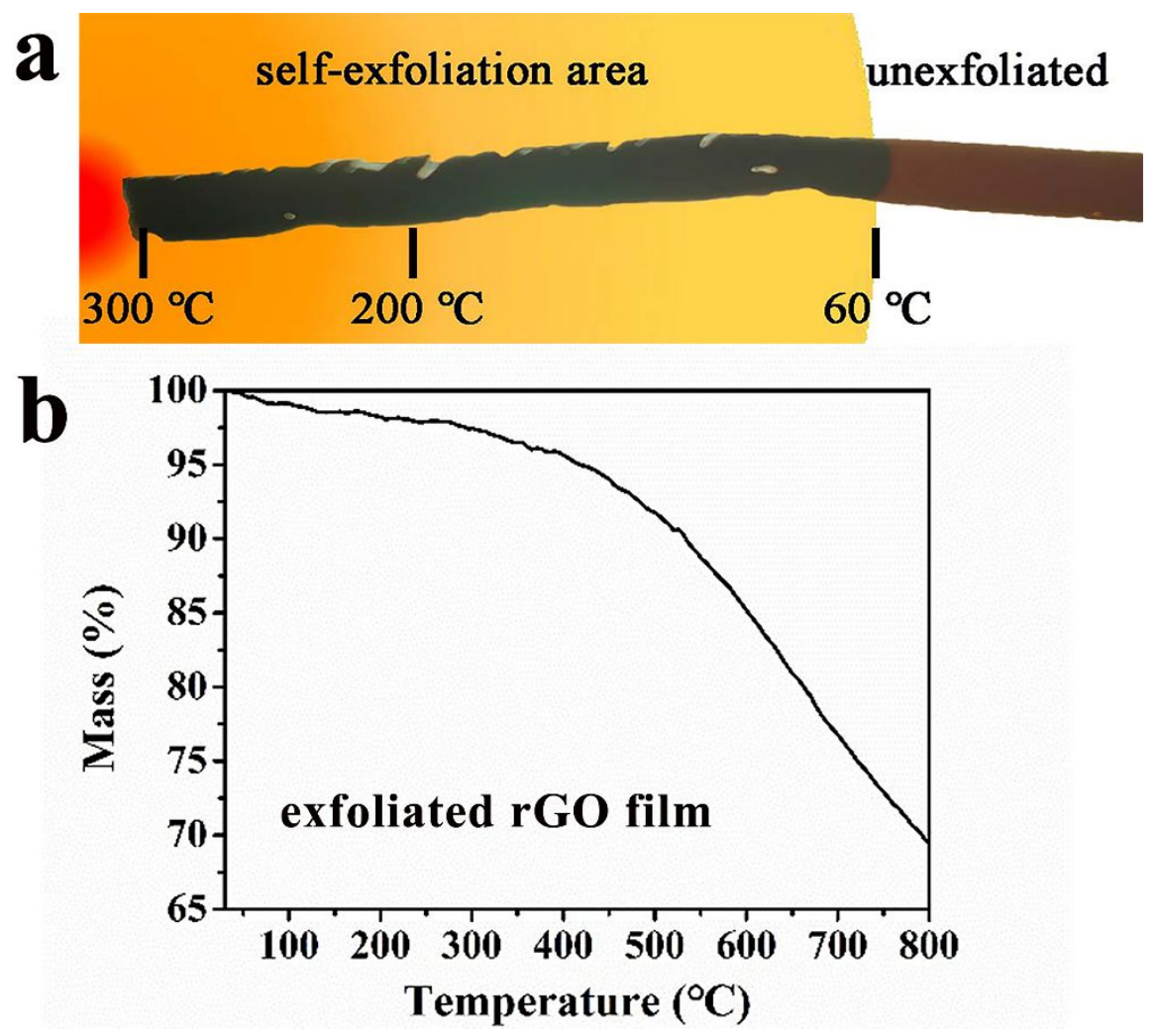

Figure S6. (a)Exfoliation of a GO stripe placed in a concentric temperature field ranging from $300{ }^{\circ} \mathrm{C}$ to room temperature. (b) TGA curve of the exfoliated rGO film.

A $10 \times 0.5 \mathrm{~cm} \mathrm{GO}$ stripe is placed in a concentric circle from $300^{\circ} \mathrm{C}$ to room temperature. After being triggered by the soldering iron heated to $300{ }^{\circ} \mathrm{C}$, the stripping continues spontaneously until the environment temperature is below $60{ }^{\circ} \mathrm{C}$. Combined with the self-exfoliation phenomenon of GO film in a constant temperature field (Figure 3a), we can conclude that the environment temperature of 60 ${ }^{\circ} \mathrm{C}$ is the lowest temperature to maintain self-exfoliation of graphite oxide film. 

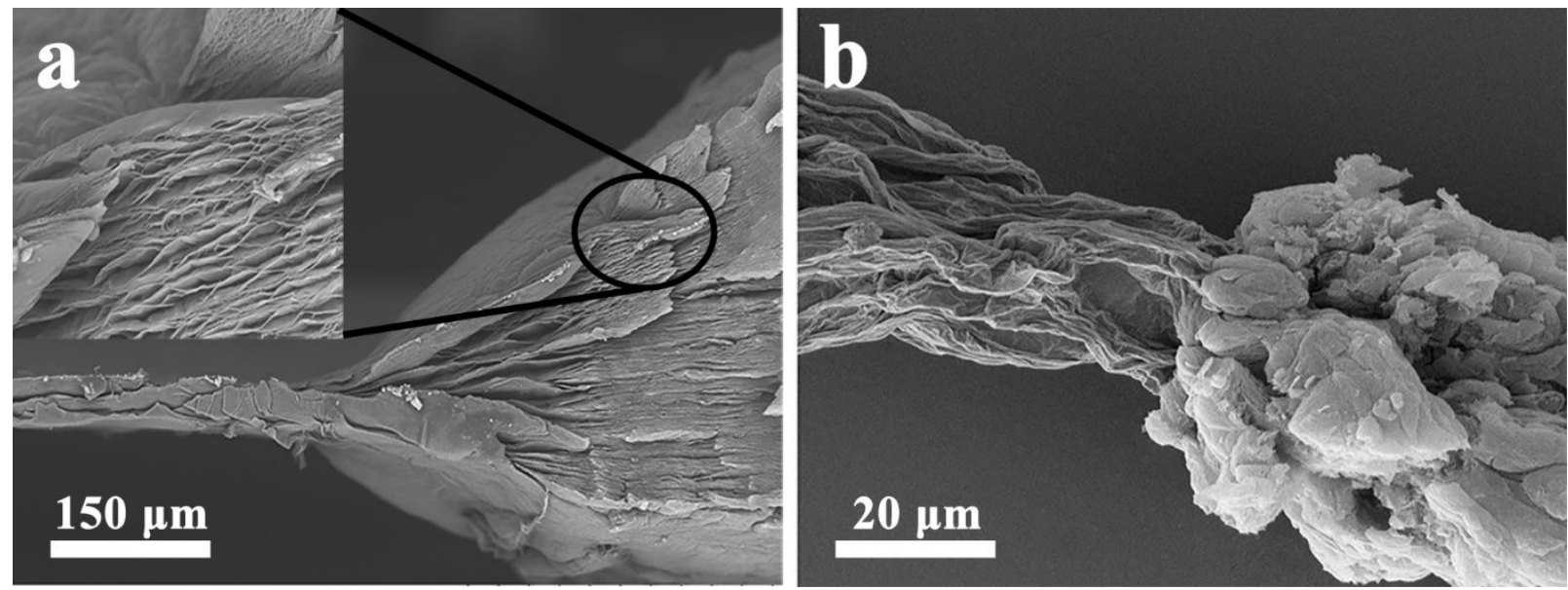

Figure S7. (a) Self-exfoliation of GO film with a thickness of $40 \mu \mathrm{m}$, (b) self-exfoliation of GO fiber.
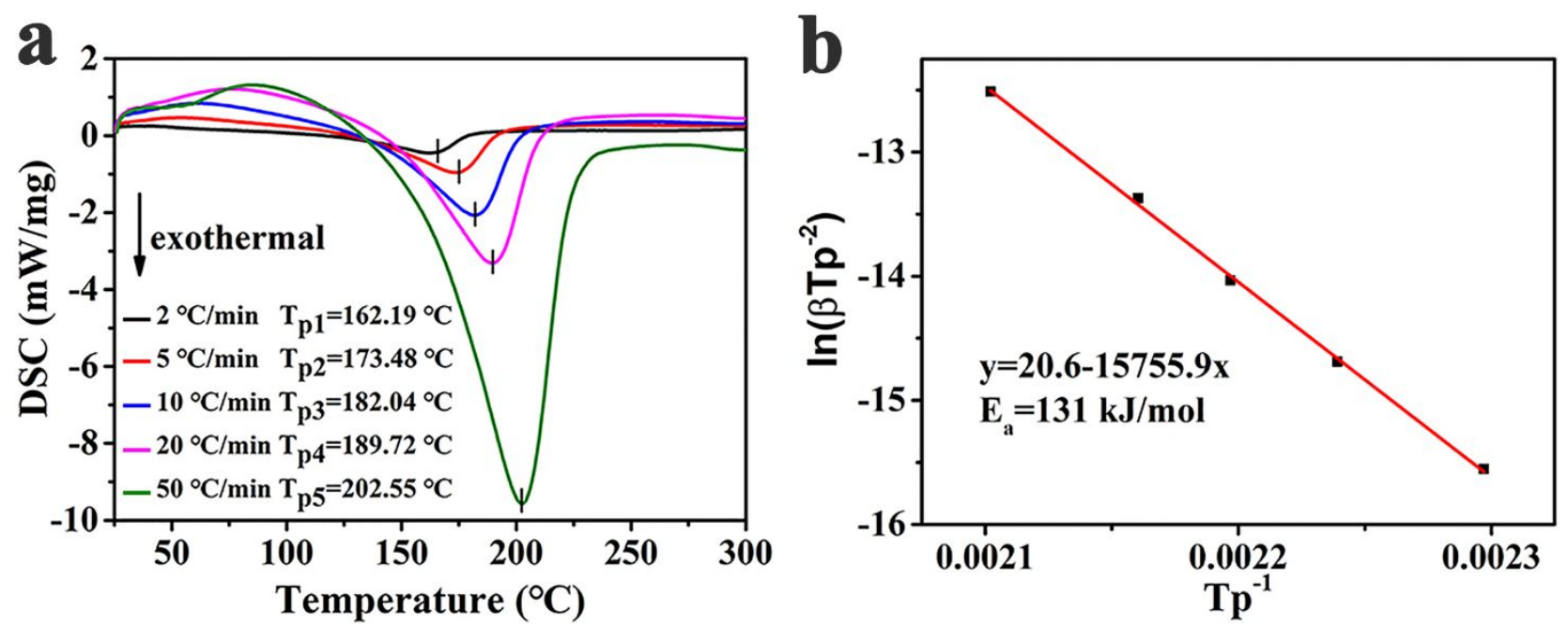

Figure S8. (a) DSC curves of GO at different heating rates $\left(2,5,10,20\right.$, and $\left.50{ }^{\circ} \mathrm{C} \cdot \mathrm{min}^{-1}\right)$, and (b) apparent activation energy $E_{a}$ of the exothermic peak of GO, calculated using the Kissinger equation ( $\beta$, heating rate; $\mathrm{T}_{\mathrm{p}}$, peak temperature).

Figure S8a show the thermal behavior of five GO films when they were heated from 25 to 300 ${ }^{\circ} \mathrm{C}$ at $2,5,10,20$, and $50{ }^{\circ} \mathrm{C} \cdot \mathrm{min}^{-1}$, respectively. The decomposition kinetics of GO exfoliation can be calculated by using Kissinger equation: ${ }^{1} \operatorname{In}\left(\beta / T_{P}{ }^{2}\right)=\operatorname{In}\left(A R / E_{a}\right)-E_{a} /\left(R T_{P}\right)$, where $\beta$ is the heating rate of GO film, $T_{P}$ is the peak temperature of corresponding DSC curve, A is pre-exponential (frequency) factor $\left(\mathrm{s}^{-1}\right), \mathrm{R}$ is the gas constant $\left(8.314 \mathrm{~J} \cdot \mathrm{mol}^{-1} \cdot \mathrm{K}^{-1}\right)$, and $\mathrm{E}_{\mathrm{a}}$ is the activation energy $\left(\mathrm{kJ} \cdot \mathrm{mol}^{-1}\right)$. According to the DSC curves generated at different heating rates (Figure S5a), we can obtain a linear computational fitting plot of $\mathrm{Tp}^{-1}$ vs. $\operatorname{In}\left(\beta \mathrm{T}_{\mathrm{p}}^{-2}\right)$, from which the activation energy $\left(\mathrm{E}_{\mathrm{a}}\right)$ is calculated to be $131 \mathrm{~kJ} \cdot \mathrm{mol}^{-1}$ (Figure S8b). The good fitting indicates the reliability of the calculated $\mathrm{E}_{\mathrm{a}}$. 

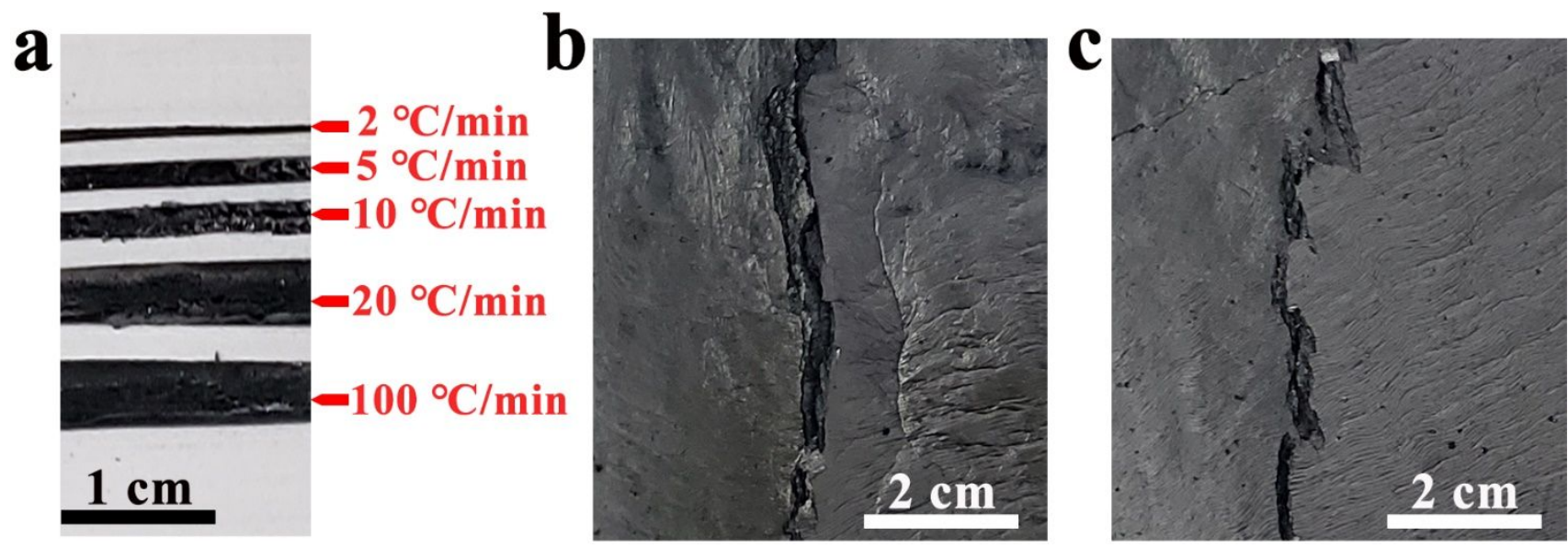

Figure S9. (a) Digital images of rGO sponges sandwiched in pages obtained at 2, 5, 10, 20, 100 ${ }^{\circ} \mathrm{C} \cdot \mathrm{min}^{-1}$, (b) digital images of folding treated $\mathrm{rGO}$ sponge obtained at $20^{\circ} \mathrm{C} \cdot \mathrm{min}^{-1}$, (c) digital images of folding treated $\mathrm{rGO}$ sponge obtained at $100^{\circ} \mathrm{C} \cdot \mathrm{min}^{-1}$,
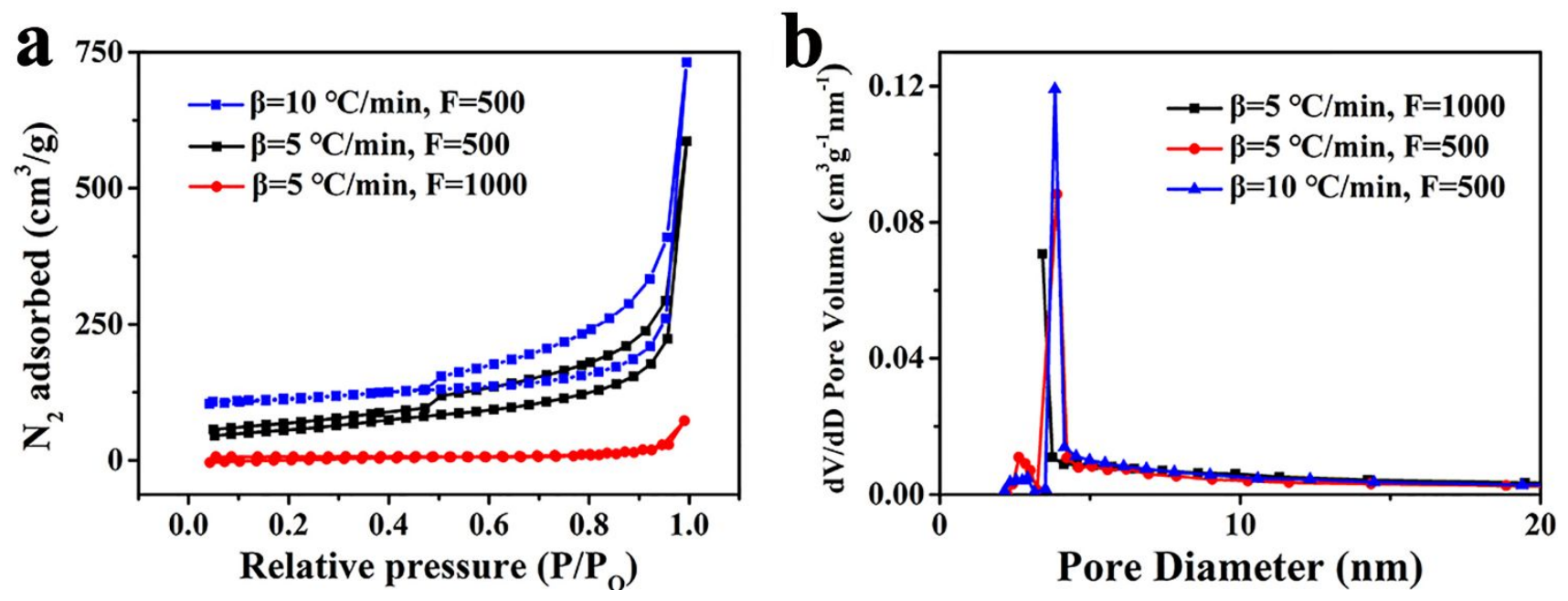

Figure S10. (a) $\mathrm{N}_{2}$ adsorption isotherms of rGO sponge obtained at different conditions, and (b) the corresponding $\mathrm{N}_{2}$ pore size distributions of the obtained $\mathrm{rGO}$ sponge. 


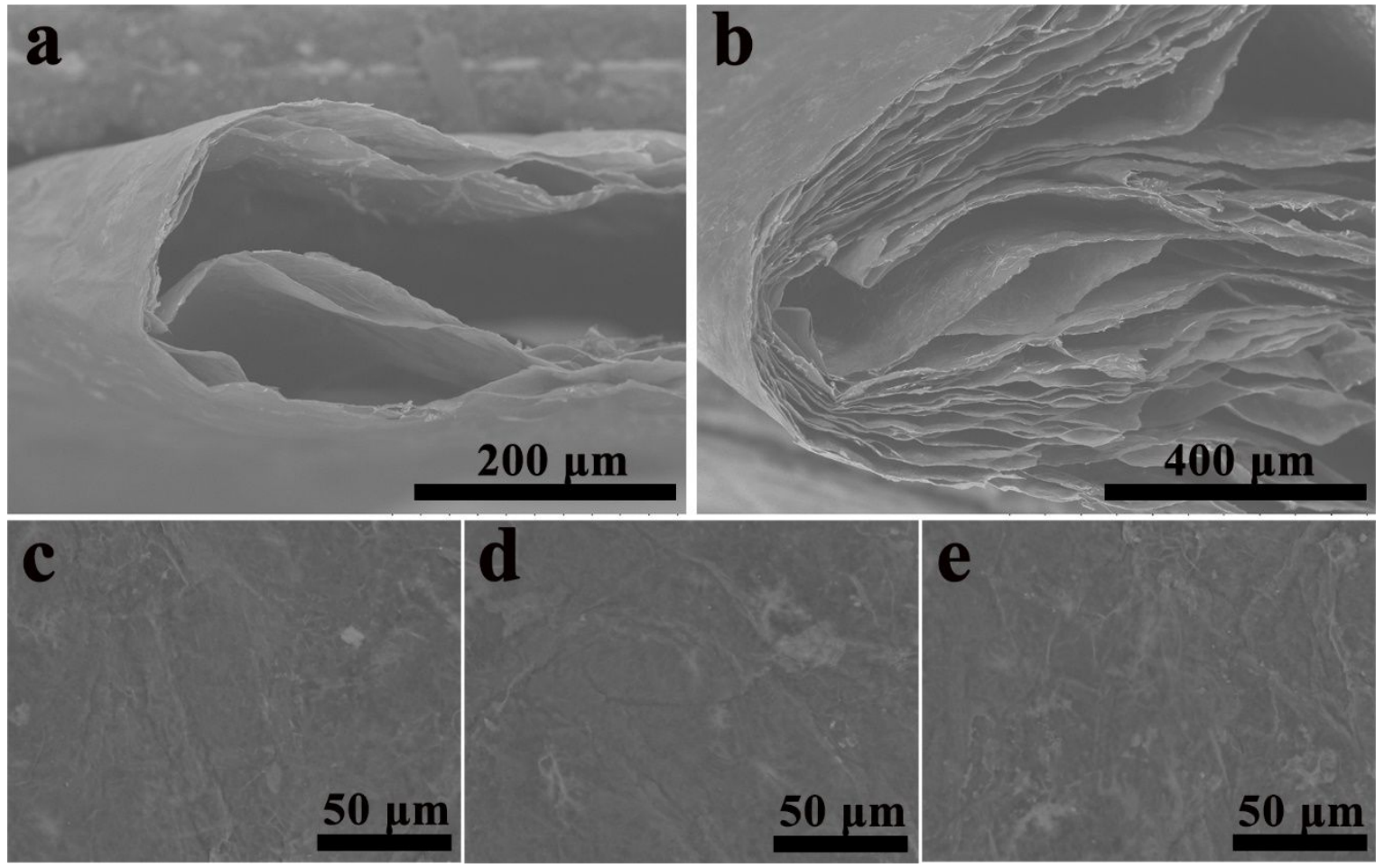

Figure S11. Cross-section SEM images of half-hold $\mathrm{rGO}$ sponges obtained with (a) $\beta=5^{\circ} \mathrm{C} \cdot \mathrm{min}^{-1}$, $\mathrm{F}=1000$; and (b) $\beta=10^{\circ} \mathrm{C} \cdot \mathrm{min}^{-1}, \mathrm{~F}=500$ after annealed, surface SEM images of (c) rGO sponge, (d) rGO sponge after half-folded, (e) rGO sponge after quarter-folded.

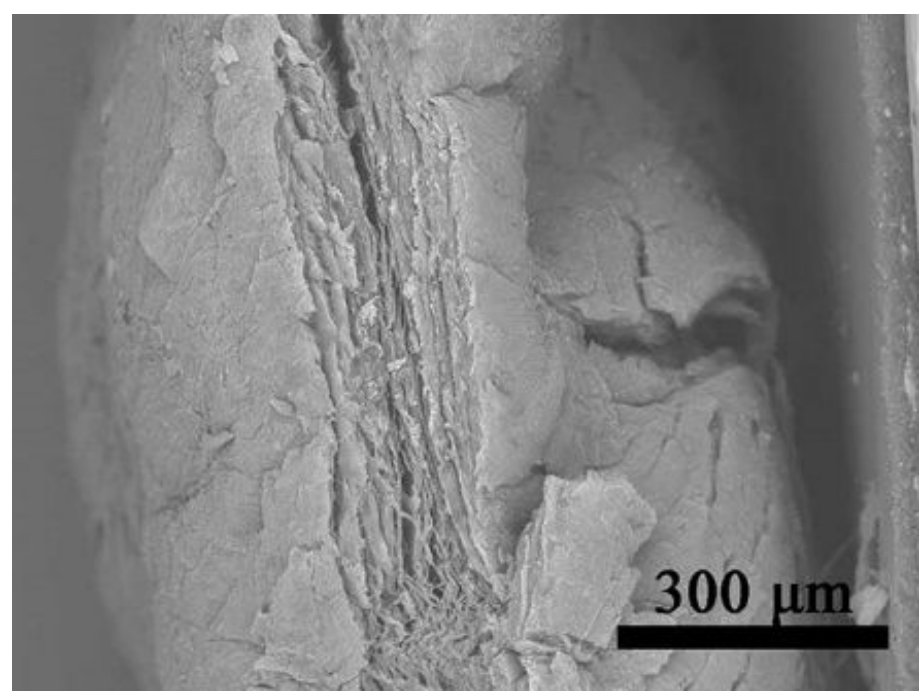

Figure S12: Cross-section SEM images of a $\mathrm{rGO}$ sponge obtained under $\beta=10^{\circ} \mathrm{C} \cdot \mathrm{min}^{-1}, \mathrm{~F}=500$, the thickness of initial film is $50 \mu \mathrm{m}$. 
a

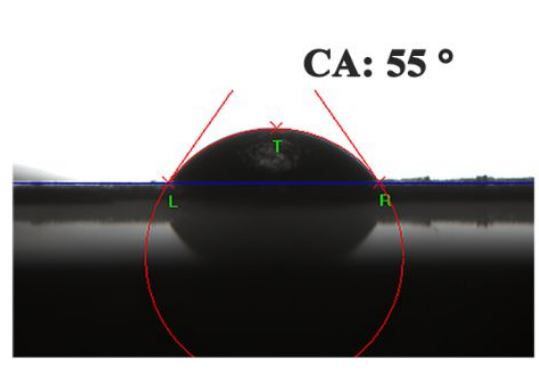

$\mathbf{b}_{1}$

1.00

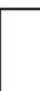

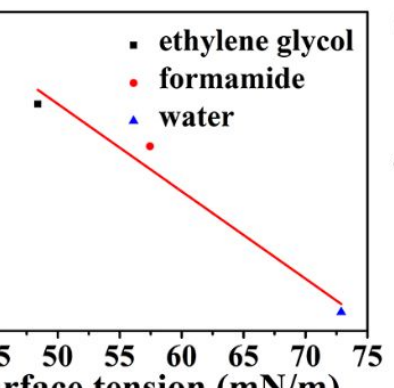

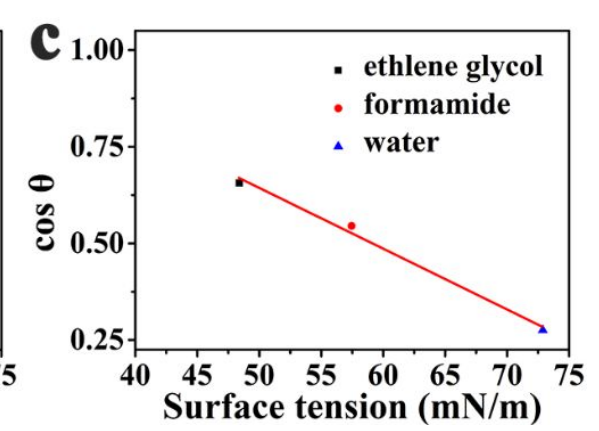

Figure S13: (a) The picture of the contact angle between aqueous electrolyte and annealed rGO sponge, and calculation of surface tension of $\mathrm{rGO}$ sponge obtained with (b) $\beta=10^{\circ} \mathrm{C} \cdot \mathrm{min}^{-1}, \mathrm{~F}=500$, and heated to $300^{\circ} \mathrm{C}$; and (c) $\beta=10^{\circ} \mathrm{C} \cdot \mathrm{min}^{-1}, \mathrm{~F}=500$, and annealed at $1050{ }^{\circ} \mathrm{C}$.

a

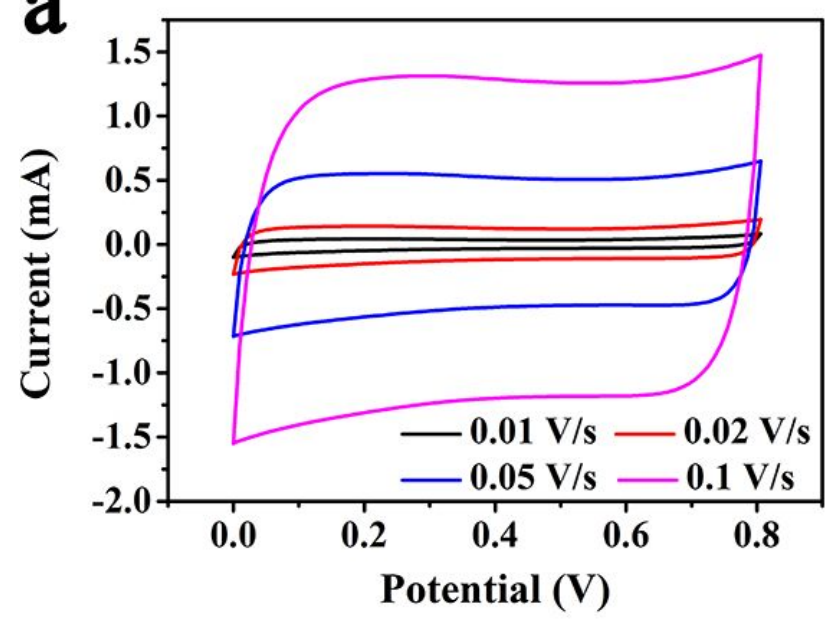

C

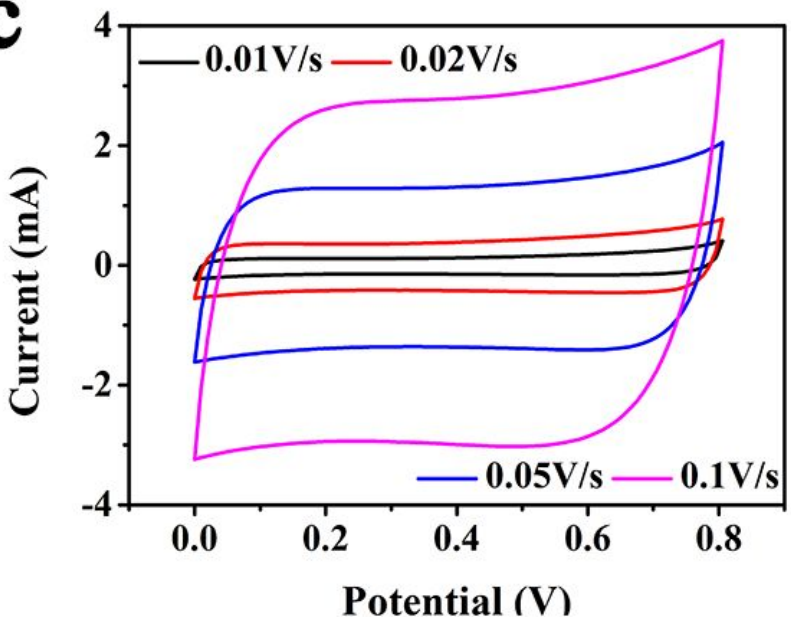

b
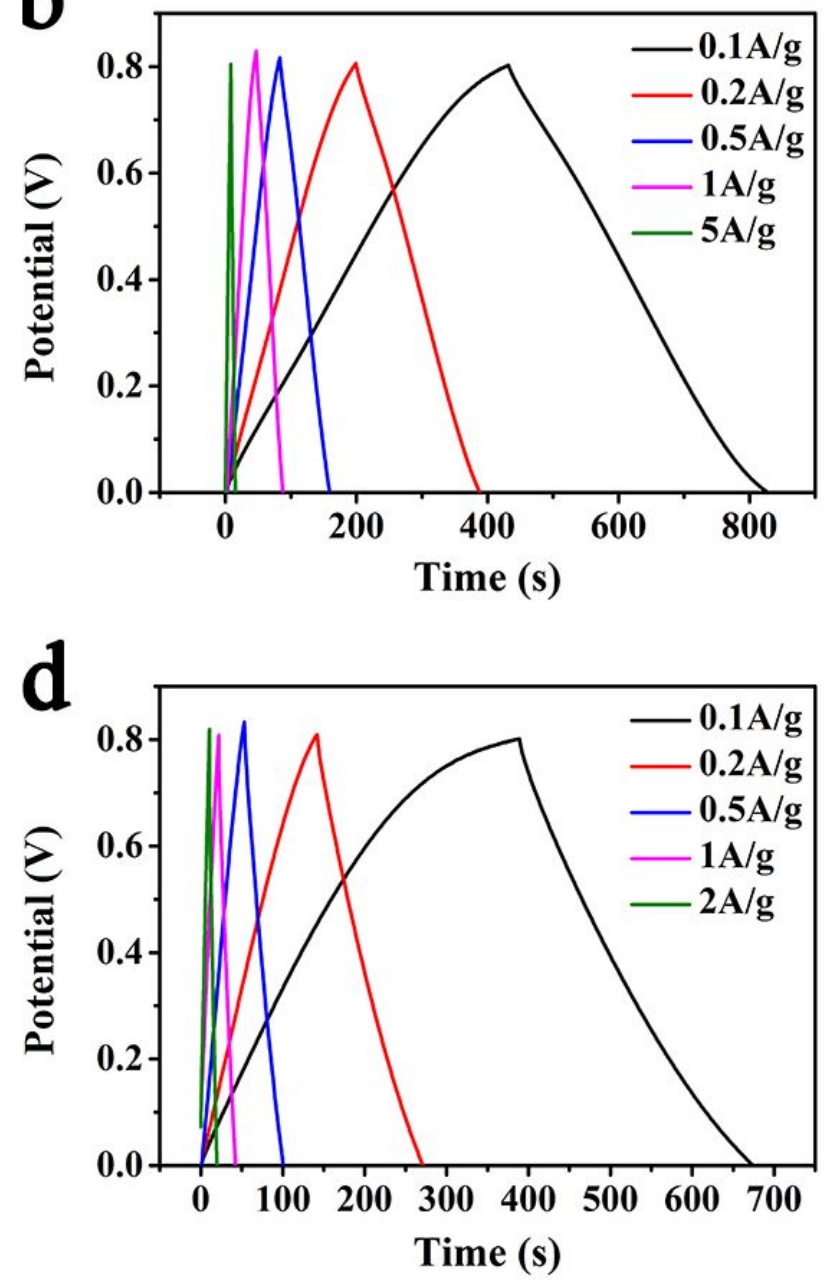

Figure S14. (a) CV curves and (b) galvanostatic current charge and discharge curves of a graphene sponge obtained with $\beta=5^{\circ} \mathrm{C} / \mathrm{min}, \mathrm{F}=500$. (c) $\mathrm{CV}$ curves and (d) galvanostatic current charge and discharge curves of a graphene sponge obtained with $\beta=5^{\circ} \mathrm{C} / \mathrm{min}, \mathrm{F}=1000$. 

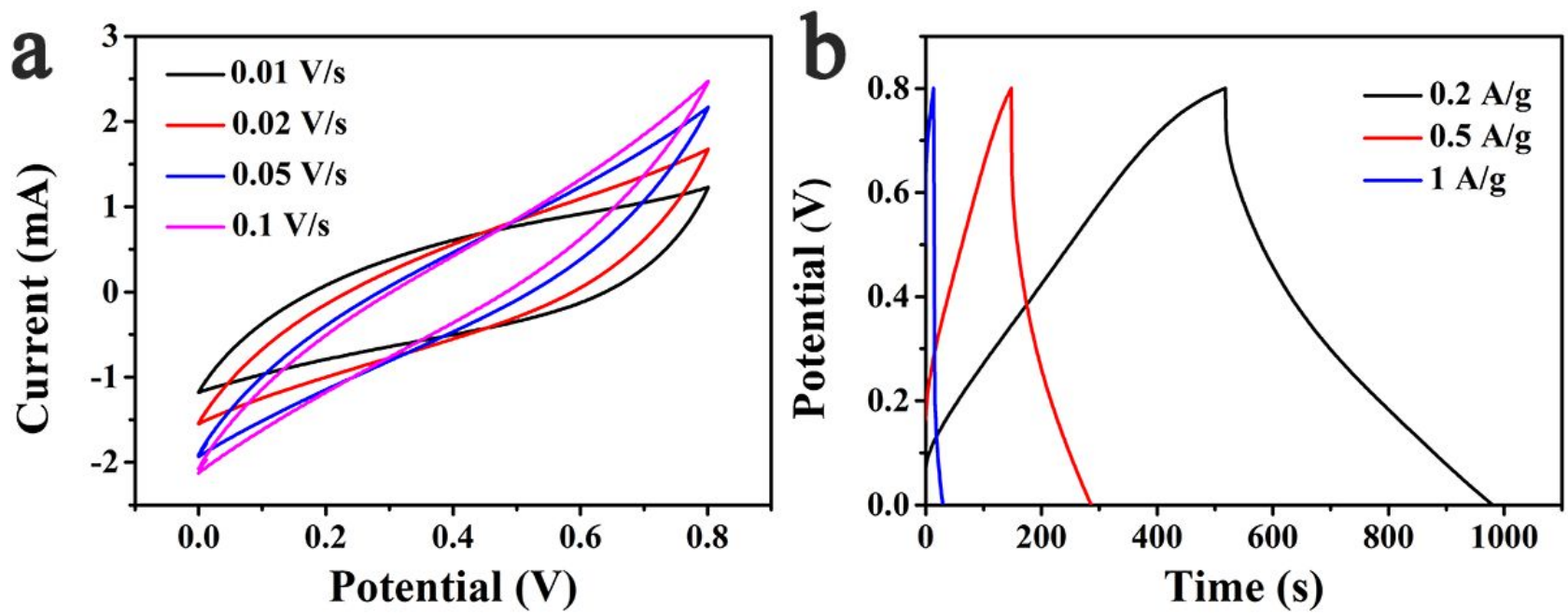

Figure S15. (a) CV curves and (b) galvanostatic current charge and discharge curves of a rGO sponge obtained with $\beta=10{ }^{\circ} \mathrm{C} \cdot \mathrm{min}^{-1}, \mathrm{~F}=500$ before annealed at $1050{ }^{\circ} \mathrm{C}$. 


\section{References}

(1) Xu, Y.; Wang, Q.; Shen, C.; Lin, Q.; Wang, P.; Lu, M., Nature 2017, 549 (7670), 78-81.

(2) Lv, W.; Tang, D.-M.; He, Y.-B.; You, C.-H.; Shi, Z.-Q.; Chen, X.-C.; Chen, C.-M.; Hou, P.-X.; Liu, C.; Yang, Q.-H., Acs Nano 2009, 3 (11), 3730-3736.

(3) Zhang, H.-B.; Wang, J.-W.; Yan, Q.; Zheng, W.-G.; Chen, C.; Yu, Z.-Z., Journal of Materials Chemistry 2011, 21 (14), 5392-5397.

(4) Qiu, Y.; Moore, S.; Hurt, R.; Kulaots, I., Carbon 2017, 111, 651-657.

(5) Chen, C.-M.; Zhang, Q.; Yang, M.-G.; Huang, C.-H.; Yang, Y.-G.; Wang, M.-Z., Carbon 2012, $50(10), 3572-3584$.

(6) Cao, J.; Qi, G.-Q.; Ke, K.; Luo, Y.; Yang, W.; Xie, B.-H.; Yang, M.-B., Journal of Materials Science 2012, 47 (13), 5097-5105.

(7) Li, S.-M.; Yang, S.-Y.; Wang, Y.-S.; Lien, C.-H.; Tien, H.-W.; Hsiao, S.-T.; Liao, W.-H.; Tsai, H.-P.; Chang, C.-L.; Ma, C.-C. M.; Hu, C.-C., Carbon 2013, 59, 418-429.

(8) Qiu, Y.; Guo, F.; Hurt, R.; Kuelaots, I., Carbon 2014, 72, 215-223.

(9) Shen, B.; Lu, D.; Zhai, W.; Zheng, W., J. Mater. Chem. C 2013, 1 (1), $50-53$. 